\title{
EDUCAÇÃO E TRABALHO EM UM CENTRO DE REEDUCAÇÃO FEMININA: UM ESTUDO DE CASO
}

\author{
Timothy Denis Ireland ${ }^{l}$ \\ Helen Halinne Rodrigues de Lucena ${ }^{1}$
}

\begin{abstract}
RESUMO: Nos presídios brasileiros, embora a oferta educativa e de formaçáo profissional ganhe prioridade nas propostas de reinserção de encarcerados, a educação e o trabalho mais competem do que se complementam. Partindo desse pressuposto, analisamos neste artigo esse binômio no Centro de Reeducação Feminina de João Pessoa (PB), com base em duas pesquisas realizadas com mulheres com experiência prisional. Para tanto, nos baseamos na compreensão de que educação e trabalho são fontes potenciais de aprendizagem e deveriam/ devem ser mais acessíveis e complementares no contexto das prisóes femininas, considerando as especificidades de gênero nelas envolvidas. Por outro lado, também entendemos que elas não devem ser vistas como garantias para o amplo propósito da ressocialização e reintegração social, sendo para isso necessária a reuniâo de outro conjunto de açôes pós-penitenciárias.
\end{abstract}

Palavras-chave: Educação e trabalho na prisão. Educação de mulheres privadas de liberdade. Reintegração social.

\section{Education and work in a women's re-education center: a case study}

ABSTRACT: Although the supply of education and vocational training, in Brazilian prisons, is given priority in proposals for the reintegration of prisoners, education and work compete rather than complement each other. Taking that premise as our

${ }^{1}$ Universidade Federal da Paraíba (UFPB) - João Pessoa (PB), Brasil.

E-mail: ireland.timothy@gmail.com; helen_ufpb@yahoo.com

DOI: 10.1590/CC0101-32622016162651 
starting point, in the present article we analyse this binomial in the Women's Re-education Centre in João Pessoa (PB), based on two surveys conducted with women with prison experience. To that end, we assume that education and work are potential sources of learning and should be more accessible and complementary in the context of women's prisons considering the specifics of gender involved in them. However, we also understand that they should not be seen as guarantees for the broad purpose of rehabilitation and social reintegration for which the junction of other post-prison actions are necessary.

Keywords: Education and work in prison. Education of women prisoners. Social reintegration.

\section{INTRODUÇÃO}

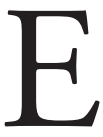

ste artigo teve como ponto de partida os resultados de uma pesquisa realizada, em 2013, no Centro de Reeducação Feminina de João Pessoa, Paraíba, com 133 mulheres encarceradas, que, entre outras variáveis, analisou dados sobre educação e trabalho. Também tomamos por referência os resultados de um estudo biográfico realizado com sete mulheres (egressas e reincidentes ${ }^{1}$ na mesma prisão em que se encontravam as mulheres da pesquisa anterior) no mesmo ano.

Salienta-se que o presídio feminino de onde são provenientes as mulheres citadas neste texto está localizado em João Pessoa (capital do Estado da Paraíba) e, na ocasião, continha 305 mulheres confinadas (249 estão no regime fechado, 42, no regime semiaberto, e 14, no regime aberto), mesmo com capacidade prevista para abrigar apenas 60 pessoas. Além disso, no mesmo ano da pesquisa, tanto o nosso como outros estudos identificaram que o referido presídio, além de superlotado, apresentava dificuldades estruturais que limitavam o desenvolvimento das atividades de ressocialização e a qualidade da vivência e da convivência de forma digna no local (BEZERRA; BRAGA; BATISTA, 2013).

Dito isso, convém registrar que, para a realização da pesquisa, a metodologia adotada no primeiro estudo foi a aplicação de questionários 
com 133 reclusas do presídio referido, objetivando levantar os seus perfis quanto às experiências profissionais e educativas antes e durante o encarceramento. No segundo estudo, os dados foram coletados por meio da história de vida de sete mulheres com experiência prisional ${ }^{2}$. Com efeito, essas tarefas implicaram no encaminhamento à Gerência de Ressocialização da Secretaria de Administração Penitenciária da Paraíba (SEAP/PB) de um pedido formal de autorização para ter acesso aos prontuários e/ou ao banco de dados existente no presídio, tendo em vista o objetivo de levantar as informações requeridas e, a partir disso, fazer uma pré-seleção das que convidaríamos a fazer parte desses estudos. $\mathrm{Na}$ referida solicitação também pedimos permissão para contatar e realizar entrevistas com egressas do sistema penitenciário (em liberdade condicional) que ainda estivessem sob a tutela do Estado e com reclusas reincidentes que tivessem regressado à prisão depois de, pelo menos, seis meses em liberdade.

Em relação ao segundo estudo, discutimos neste artigo apenas as categorias que disseram respeito ao trabalho (e a qualificação profissional) e à escola em suas trajetórias no ambiente da prisão. Seus resultados nos ajudaram a refletir sobre os limites e as possibilidades das aprendizagens no contexto da prisão.

Ao discutir a prisão feminina de João Pessoa como espaço de aprendizagens, partimos do pressuposto de que as prisóes, embora possuam uma peculiaridade antieducativa, constituem-se em lócus de múltiplas possibilidades de aprendizagens, construídas no contexto intramuros a partir das experiências que nele as detentas vivenciam e que adotam como alternativa para lidar com as privaçóes do encarceramento, assim como estratégia para abreviar a pena.

\section{ENTRE POSSIBILIDADES E LIMITES DA APRENDIZAGEM AO LONGO DA VIDA NA PRISÃO}

A precariedade do atendimento educacional na prisão e a existência de poucos profissionais de educação preparados para atuarem no contexto intramuros são alguns dos muitos fatores ${ }^{3}$ que coíbem qualquer proposta de educação nas prisóes que se despregue da lógica repressora desses contextos. Eles dificultam a instalação de um projeto educativo 
capaz de elevar o potencial de aprendizagem das pessoas encarceradas, o qual é considerado componente significativo do processo de educação e aprendizagem ao longo da vida, assim como oportunidade para o redirecionamento da vida dos sujeitos (BRASIL, 2010).

Dessa feita, as reflexões sobre a aprendizagem aqui perfiladas baseiam-se no conceito ampliado de educação e aprendizagem ao longo da vida, adotado nas últimas Conferências Internacionais de Educação de Adultos, realizadas em Hamburgo (UNESCO, 1997) e em Belém (UNESCO, 2009), para reafirmar a multiplicidade de contextos onde ela pode ocorrer e a diversidade de interesses e necessidades educativas dos diferentes grupos sociais. Nesse contexto, a Educação de Adultos passou a englobar:

[...] todo processo de aprendizagem, formal ou informal, em que pessoas consideradas adultas pela sociedade desenvolvem suas capacidades, enriquecem seu conhecimento e aperfeiçoam suas qualificações técnicas e profissionais, ou as redirecionam, para atender suas necessidades e as de sua sociedade. (UNESCO, 2010, p. 5)

Além de mudanças no campo conceitual, a Educação de Jovens e Adultos também foi evocada para contribuir para a recuperação de homens e mulheres em situação de privação de liberdade em estabelecimentos penais. Assim, a educação em estabelecimentos penais ganhou espaço na agenda político-educativa brasileira como um direito subjetivo da pessoa privada de liberdade e uma ferramenta indispensável para a sua reinserção social e para a redução dos índices de reincidência. Surge, portanto, o desafio de uma educação em prisóes atrelada aos princípios da Educação de Jovens e Adultos e, por sua vez, às práticas que incorporam o conceito de aprendizagem ao longo da vida.

Aprendizagem e educação ao longo da vida aparecem entáo como uma alternativa favorável a um projeto educativo nas prisóes que pressuponha contribuir

[...] com que os reclusos gostem de aprender, mostrar que eles são capazes de escrever, de dedicar sua atenção a uma tarefa, de estabelecer para si mesmos objetivos a atingir individual e coletivamente em diferentes tipos de projetos. (DE MAEYER, 2006, p. 27) 
Compreendemos, portanto, esse paradigma sob um prisma que ultrapassa a dimensão econômica, reconhecendo, para além disso, os benefícios sociais oferecidos aos sujeitos (ÁVILA, 2005; ALVES, 2010).

Nesse contexto, adquire relevância no espaço da prisão um projeto educativo em que a articulação entre as atividades (educação escolar, formação profissional e trabalho, por exemplo) se constitua referência fundamental para a ampliação do leque de oportunidades de aprendizagens às pessoas encarceradas. Essa articulação - em que as aprendizagens formais, não formais e informais transitam e se complementam entre si (ÁVILA, 2005; ALVES, 2010) — consolida uma proposta educativa baseada nos pilares do paradigma da aprendizagem e educação ao longo da vida e, ao mesmo tempo, é "[...] um desafio dos mais importantes para todos aqueles que pensam a educação nas prisóes” (HADDAD, 2010, p. 122).

Há, entretanto, laços complexos entre a sua materialização e as lógicas próprias que regulam as prisóes. Os projetos e as práticas com intencionalidade educativa, quando existem na prisão, são vistos como concorrentes (HADDAD, 2010), provocando um entrave à efetivação de ações articuladas.

Reconhecendo as lacunas do Estado no que tange à oferta de oportunidades de aprendizagens para pessoas presas e a dificuldade em lhes oferecer maiores chances de reintegraçáo social, apresentamos em seguida alguns dados que indicam a restrita oferta e a precária participação dessas mulheres em atividades educativas e laborais no presídio feminino de Joáo Pessoa.

\section{O QUE DIZEM AS MULHERES SOBRE SUAS EXPERIÊNCIAS E APRENDIZAGENS NA PRISÃO?}

Não é novidade que as pessoas presas no Brasil são oriundas das camadas sociais mais pobres, filhas de famílias que não tiveram acesso à educação, tampouco a uma formação profissional capaz de incluí-las no mercado formal de trabalho (IRELAND; LUCENA, 2013). Na prisão feminina de João Pessoa essas características sociais se fizeram visíveis quando levantamos o perfil sociodemográfico das reclusas. 
$\mathrm{Na}$ amostra desta pesquisa, que reuniu 133 mulheres encarceradas, observamos que 85 (64\%) delas estavam na faixa etária entre 18 e 29 anos de idade, 79 (59\%) obtinham experiência escolar apenas até o ensino fundamental e 100 (75\%) haviam ocupado postos de trabalhos mal remunerados e desprovidos de proteção social antes de enveredarem por mundos ligados ao crime.

Em face desse perfil, confirma-se o que Lemgruber (1983) já apontava há décadas, em estudo pioneiro que analisou a situação de uma prisão de mulheres, ou seja,

a opção prioritária da seletividade do sistema punitivo nas camadas e categorias sociais mais desfavorecidas, reforçando, pois, as noções de vulnerabilidade de segmentos específicos da sociedade (CHIES, 2005, p. 3),

como no caso das mulheres.

Após Lemgruber (1983), estudos mais recentes (FRANÇA, 2014; CERNEKA, 2009) também apontam que

[...] as mulheres encarceradas possuem condiçóes específicas de vulnerabilidade e demandam atenção especial do Estado, que tem o dever de dar maior estima a essa situaçáo, o que lamentavelmente não vem sendo observado (OLIVEIRA; SANTOS, 2012, p. 237).

No presídio feminino de João Pessoa, a situação não é diferente. Ou seja, o perfil das mulheres que lá se encontram revela uma demanda expressiva para o fortalecimento de programas e projetos de ressocialização específicos, ligados à educação e ao trabalho, de modo que as mulheres possam ampliar o leque de oportunidades de aprendizagens e enxergar a possibilidade de fazerem outras coisas, terem outras atitudes, desenvolverem outros projetos, despertarem outras afeiçóes, etc. (DE MAEYER, 2013).

Mas apesar dessa demanda, infelizmente, os dados do primeiro estudo são desanimadores, pois revelam que as açóes de educação e trabalho ofertadas no referido presídio abarcavam, no período da pesquisa, 
uma pequena parcela da amostra selecionada. A larga maioria das detentas não estava envolvida ou nunca se envolveu em atividades laborais e educativas na prisão. Assim, "a escassez do Estado enquanto gerador de novas habilidades para as prisioneiras colabora para manter a vulnerabilidade social desta população" (LIMA et al., 2013, p. 450).

Vimos, por exemplo, essa escassez nos dados coletados com as mulheres sobre a participação em atividades laborativas no presídio feminino de João Pessoa. Das 133 que responderam aos questionários, apenas $41(31 \%)$ disseram estar exercendo ou ter exercido algum tipo trabalho na prisão. As 92 (69\%) restantes informaram não estar trabalhando ou nunca terem trabalhado enquanto reclusas. O mesmo verificamos quando se referiram à participação na educação formal oferecida no presídio, à realização de exames de certificação escolar (Exame Nacional para Certificação de Competências de Jovens e Adultos - ENCCEJA, Programa Nacional de Inclusão de Jovens - PROJOVEM, Exame Nacional do Ensino Médio - ENEM) e ao envolvimento em atividades de qualificação profissional. Nesses quesitos, constatamos que apenas 34 mulheres, o que representa $25 \%$ do total da amostra, estavam estudando ou já haviam estudado no espaço prisional, 91(68\%) nunca fizeram nenhum exame para certificação de escolaridade e apenas 17 (13\%) participavam ou já participaram de cursos de qualificação oferecidos na prisão.

Esses dados, quando confrontados com as falas de algumas mulheres sobre suas experiências de educação e trabalho na prisão, nos dão elementos para pensar as fragilidades da oferta dessas atividades na prisão. Fragilidades essas que aqui refletimos apenas no campo da ausência dessa oferta de educaçáo, considerando que ao estender o debate sobre os tipos de oferta, quando existe, demonstram não serem suficientes ou adequadas à preparaçáo do preso (e em particular da mulher presa) para o retorno à sociedade. Em alguns casos, como alertou Lemgruber (1983, p. 67) há algum tempo, “[...] a exploração do trabalho dos presos com uma retribuição irrisória pode, ao contrário, fortalecer seu animus delinquendi".

Nessa discussão, não menos importante é atentar para experiências vivenciadas na escola da prisão. Sobre essas experiências, que 
dizem respeito ao tipo de oferta educativa na prisão feminina de João Pessoa, as detentas assim revelaram:

Não é bom, não. Porque não vem nem professor, só vem fazer prova. A gente faz prova sem saber de nada. Se não assistir televisão... Como assim? Porque a televisão que ensina, jornal nacional, esses negócios, né? Globo repórter... ensina muita coisa do mundo, né? Então. A linguagem... tudo! Se não for a televisão a gente tira zero! [...]. E os professores? $E$, porque não era frequentemente. [...]. Uma vez ou duas vezes por mês era que eles vinham. Dificilmente! Não era frequente... não era frequente!' (Trecho do depoimento de Iara, egressa, 36 anos, sobre a escola/o estudo na prisão).

Eu estudava a quarta, a terceira, porque é tudo misturado. As coisas que eu já estudei nas quinta séries eu estudei aqui. [...] [É bom para] Ocupar a mente! [...]. Eu estudei mas... porque... assim... a gente estuda, mas não estuda todos os dias, né? É umas vezes perdida, tem tempo que elas [as professoras] não vem. Aí eu não estudei mais, não. (Trecho do depoimento de Araci, reincidente, 31 anos, sobre a escola/o estudo na prisão).

Só tem aula para o ensino fundamental porque não tem espaço. Aí [o ensino médio] é só o supletivo, que é de ano em ano que eles fazem. [...]. É muita dificuldade! A pessoa estuda sozinha. (Trecho do depoimento de Açucena, reincidente, 28 anos, sobre a escola/o estudo na prisão).

[...] era só pra sair dentro da cela, só pra ocupar minha mente, porque não tava fazendo nada mesmo, só pra sair. [...]. Aí então, eu fiz por isso! Pra sair de dentro da cela, como muitas lá fazem também. [...]. Acho que até na maioria das vezes, elas [as outras reclusas] se matriculam nessa intenção que eu tinha: de sair, de respirar um pouco o ar da noite, [...], só em você sair de dentro daquele inferno! [...]. Não é pra aprender, não, é só pra sair de dentro da cela mesmo. A verdade é essa mesmo! [...]. Não aprende nada ali, não. (Trecho do depoimento de Maiara, egressa, 33 anos, sobre a escola/o estudo na prisão). 
Os dados sobre a participação nas atividades educativas são elucidativos de que embora nos últimos anos a agenda pública tenha colocado em destaque a educação em prisóes e reconhecido a sua importância como "[...] ferramenta adequada para o processo formativo [da pessoa presa], no sentido de produzir mudanças de atitudes e contribuir para a integração social" (ONOFRE, 2011, p. 275), na prática, há um longo caminho para o alcance desse objetivo. Reconhecemos, ainda, que nas condiçôes em que as práticas educativas são desenvolvidas nesse contexto, é improvável que elas sejam reconhecidas pelas reclusas como oportunidades de desenvolvimento de suas potencialidades e como alternativas reais de projetarem um novo caminho em direção ao retorno à sociedade. Salienta-se que, por se tratar de uma oferta educativa para mulheres, deveria se levar em conta as especificidades da sua identidade de gênero, podendo isso ser um elemento crucial para motivá-las a participarem da escola na prisão. Assim afirmamos por entendermos que, para a mulher jovem e adulta, o retorno à escola é quase sempre uma decisão que tem a ver com os tipos de vínculos afetivos construídos ao longo da vida, com o desejo de melhorar as condiçóes de vida dos entes familiares, ou como forma de crescimento pessoal e profissional, sendo essas algumas das razóes pelas quais defendemos uma educação na prisão atrelada ao trabalho (ou à formação profissional). Nesse sentido, concordamos com Cunha (2010, p. 176), quando afirma que

[...], a educação deve se integrar a uma política séria de qualificação profissional e trabalho no cárcere. As atividades de trabalho e educação na prisão não podem ser encaradas como mais uma ocupação para a reeducanda cumprir seu tempo de pena mais tranquila, mas deve fazer parte de um projeto consistente de resgate da dignidade humana e possibilidade de novos sonhos e rumos, quando do cumprimento desta pena. A ação educativa como meio para a ressocializaçáo deve resgatar a dignidade humana das mulheres presas, permitindo a atividade criadora e a construçấo da autonomia.

Em se tratando de trabalho, foi curioso observar as ocupaçóes das 41 mulheres (31\% do total da amostra) que declararam, no primeiro estudo, estar trabalhando na prisão. As ocupaçóes que as reclusas disse- 
ram exercer, algumas com nomes inusitados, são, na maior parte, as de apoio ao estabelecimento penal (serviços gerais, cozinheira, chamadora, carregadora de feira, transportadora de objetos para a cozinha) e as de costura em uma fábrica existente dentro do presídio, em uma parceria com a iniciativa privada, assim como em um ateliê de bonecas.

Os depoimentos das mulheres que narraram suas histórias de vida revelam que o trabalho, quando ofertado na prisão, ou não tem qualquer relação com as experiências profissionais e habilidades anteriores ao encarceramento, ou não se adéqua às exigências e às necessidades do mercado de trabalho além das grades. A declaração abaixo é ilustrativa dessa realidade:

Eu bordava, cozinhava. Eu cozinhei também lá na cozinha. Eu fiz muita coisa boa lá dentro, muita coisa boa mesmo! Agora o problema foi... como eu disse a você... é porque na rua não tem alguém pra pegar essas pessoas. Não tem as meninas das bonecas? Você já viu? Olhe, devia abrir uma casa, né? Que quando saisse pra semiaberta, ai tem uma pessoa já pra ficar com aquelas meninas que faz aquelas bonecas, pras bonecas ir pras lojas, pra elas ganhar os dinheirinhos delas, né? Mas não, quando as meninas saem ficam tudo de mãos abanando! Ninguém ajuda! Porque na verdade, na verdade, devia abrir uma empresa pra elas, só pra apenadas, né? Quem quisesse trabalhar também, né? Porque quando tá lá dentro é uma coisa, se esforçando pra trabalhar só pra ganhar nome, né? Ai quando sai pronto, muda tudo! (Trecho do depoimento de Iracema, egressa, 44 anos, sobre as experiências laborativas na prisão).

Ficam claros, portanto, os muitos limites da proposta de ressocialização pelo trabalho no Centro de Reeducação Feminina de João Pessoa (PB). Souza (2006, p. 16) reforça esse argumento quando diz que:

A falta de apoio familiar, as reduzidas possibilidades de trabalho, de formação profissional, de lazer e a falta de acesso a bens materiais básicos tornam mais difícil a vida da detenta dentro da prisão e quando de seu retorno à liberdade. Nesse sentido, pode-se afirmar que a prisão empobrece ou agrava a pobreza preexistente. 
A propósito, vale frisar que além dessas lacunas no âmbito da oferta laborativa na prisão, a aceitação das mulheres pelos trabalhos ofertados, quando ocorria, devia-se, principalmente, segundo seus depoimentos, à possibilidade de receberem alguma remuneração e de ocuparem o tempo ocioso característico do encarceramento, conforme revelaram Maiara e Araci.

Era tão bom quando a gente recebia. Era muito ótimo! Independente de quanto fosse, era ótimo! Só em você tá ali e comprar as coisinhas que você quer: era um xampu, era um negócio, uma calcinha, tá entendendo? Não tava pedindo. (Trecho do depoimento de Maiara, egressa, 33 anos, sobre as experiências laborativas na prisão).

[Trabalhei nos] Serviços gerais, [...]. Carregando peso, limpando as fossas, trabalhando com cimento. [...]. Distrai a mente, ocupa mais... e procura se afastar das coisas erradas, né? Porque se misturar, vai pra o castigo, vai sujar sua ficha e você perde seu emprego. [...], a gente ganhava uma mixariazinha que já servia pra muita coisa... pra comprar um cigarro, comprar uma bolacha, comprava um negócio ou outro que a gente precise. (Trecho do depoimento de Araci, reincidente, 31 anos, sobre as experiências laborativas na prisão).

De maneira geral, o que se percebe é que as atividades oferecidas na prisão são voltadas, prioritariamente, à ordenação do espaço prisional e têm "[...] finalidades essencialmente laborterápicas, com reflexos positivos na disciplina, na diminuição das tensões e da ociosidade" (SILVA, 2001, p. 30). Para exercê-las não se exige qualquer qualificação, confirmando-se, pois, o que disse Wanderer (2012, p. 34): “[...] que os trabalhos oferecidos aos presos não são capazes de produzir o fim que ela almeja, qual seja, a profissionalização do condenado", tampouco de atender às expectativas e aos interesses das detentas, de maneira a tornar-se em "um caminho real para uma vida nova e uma perspectiva para um futuro longe da prisão" (LIMA et al., 2013, p. 454).

Importante também destacar a explícita reprodução de protótipos de gênero nas ocupaçóes exercidas pelas mulheres e que, não por acaso, reforçam os papéis socialmente aceitos na sociedade. Assim afirmamos porque, entre as entrevistadas, as ocupaçóes ofertadas divergiram segundo 
a identidade de gênero revelada. Para umas (as que se declaravam heterossexuais), as ocupaçóes que desenvolviam na prisão expressavam a opção do estado em reforçar determinada "carreira feminina" a ser seguida na reentrada à sociedade (bordadeira, costureira, artesã, cozinheira, etc.). Para outras (as que apresentavam características físicas extremamente masculinizadas e se declaravam lésbicas), as ocupaçôes desenvolvidas eram mais ligadas ao serviço pesado, na área dos serviços gerais, como no caso de Araci. Essas reflexôes sobre o trabalho feminino na prisão são reforçadas por Chies e Varela (2007), que entendem ter esse trabalho pouca significância para as perspectivas de acesso ao mundo do trabalho formal. Segundo eles, "O artesanato, a costura, a faxina, a cozinha, sugerem mais uma 'alternativa’ de trabalho autônomo e precário do que uma efetiva possibilidade de emprego" (CHIES; VARELA, 2007, p. 10).

Em suma, embora reconheçamos que as oportunidades de trabalho, dentro da prisão, não garantem à pessoa presa (em particular à mulher) uma ocupação no mercado formal de trabalho ao sair dela, "[...] diante do grande número de profissionais qualificados desempregados [...]" (JULIÃO, 2007, p. 45) consideramos que a ampliação da oferta para atender à demanda da população carcerária deveria constituir-se um compromisso das políticas penitenciárias, uma vez que o trabalho, para além de outros benefícios, configura o conteúdo de uma atividade educativa e, como tal, incide (mesmo em um contexto como o da prisão) no exercício e no fortalecimento da consciência cidadã (PIECK, 1997), sendo isso um elemento importante do ideal ressocializador.

Coincidência ou não, os dados das duas pesquisas que aqui nos reportamos também revelaram que pouquíssimas detentas participavam ou já participaram no presídio de cursos de qualificação profissional. Das 133 mulheres da primeira pesquisa, 115 (86\%) disseram não participar ou ter participado em atividades dessa natureza na prisão. Entre as que participaram (18), os cursos de qualificação realizados (pizzaiolo, cabeleireira, manicure, doces e salgados, costureira, confeitaria, crochê), mesmo convergindo com aquele ideal de carreira feminina, atendiam, momentaneamente, as suas expectativas nesse âmbito. 
$\mathrm{Na}$ mesma direção, entre as mulheres que narraram suas histórias de vida na prisão, destacamos os depoimentos abaixo pelas semelhanças com os resultados da pesquisa anterior a esse respeito.

Lá nunca teve isso, não. [...]. Lá ia um povo pra lá ajeitar o cabelo da gente, né? De ano em ano eles iam, um pessoal. Mas vocês não aprendiam? Não. Nunca fizeram isso pra nós, não. A não ser muito trabalho pra a gente fazer, mas curso? [...]. (Trecho do depoimento de Iracema, egressa, 44 anos, sobre as experiências de formação profissional na prisão).

Participava quando tinha. Teve um de depilação, teve de cabeleireiro, só que eram só as selecionadas. Eram selecionadas as pessoas que iam fazer esses cursos. [...]. (Trecho do depoimento de Iara, egressa, 36 anos, sobre as experiências de formação profissional na prisão).

Da outra vez não tinha [refere-se a sua primeira prisão]. Não tinha, não. E dessa vez? Teve vários, né? Mas só que não tinha vaga. E agora vai ter novamente outros cursos. Já teve uma palestra falando e tudo. Vai ter de maquiagem, $e$ depois desse de maquiagem vai ter de culinária básica e outros tipos. (Trecho do depoimento de Açucena, reincidente, 28 anos, sobre as experiências de formação profissional na prisão).

Esses dados, que nos aspectos mais relevantes se assemelham àqueles referentes à demanda por trabalho e educação nos espaços prisionais, exibem a inoperância dos processos de ressocialização implementados no sistema penitenciário brasileiro e, particularmente, no presídio feminino de João Pessoa.

Tentar entendê-los em sua inteireza certamente demandaria enveredar por muitas frentes de análises, dentre elas: a que envolve a defesa por uma escola associada à qualificação profissional e em favor da articulação entre educação e trabalho, reconhecendo ao mesmo tempo a incerta relação entre a qualificação profissional e a garantia de trabalho após a saída da prisáo; o papel e o dever do Estado e da sociedade na implementação e fiscalização das políticas, projetos e 
programas de caráter ressocializador; o poder da gestão dos presídios na aplicação (ou negação) das propostas políticas relacionadas a essas demandas; entre outras.

\section{CONSIDERAÇÕES FINAIS}

Neste artigo, procuramos contribuir para o debate sobre as aprendizagens que se constroem na prisão, pelo viés da oferta e da articulação das atividades educativas (escolarizadas), laborativas e de qualificação profissional nesse contexto. A conclusão a que chegamos passa por quatro argumentos.

Primeiro: não é apenas a articulação entre as práticas prisionais que precisa ser posta em prática no presídio feminino de João Pessoa, mas a própria oferta de atividades ligadas aos campos da educação, da qualificação profissional, do trabalho, etc., que precisa ser ampliada para o atendimento da efetiva demanda da populaçáo carcerária feminina. Segundo: a oferta educativa na prisão, além de ampliada, precisa configurar-se como algo que ofereça sentido para a vida das detentas, pois, da maneira que é ofertada dificilmente contribuirá para lhes despertar o interesse pelos estudos, tampouco para servir como instrumento de ressignificação de suas biografias. Terceiro: apesar do valor atribuído pelas prisioneiras às aprendizagens pelo trabalho e pela qualificação profissional ofertadas na prisão, estas, além de serem reduzidas e precárias, sinalizam náo surtir efeitos positivos e concretos em suas vidas no contexto extramuros, dada a discrepância entre o que se aprende dentro dela e as exigências reais do mercado de trabalho formal para além das grades. Por último, o quarto argumento tem a ver com a compreensão dos limites das políticas e práticas educativas em meio prisional, inclusive as que se relacionam com os processos formativos ligados ao trabalho. Embora esses se afigurem como fundamentais ao processo de reintegração social, não podem ser considerados uma garantia para o tão amplo propósito da ressocialização. Fazem-se necessários, também, o desalheamento da sociedade para com os sujeitos presos e egressos da prisão e a construção de políticas pós-penitenciárias consistentes que, atreladas aos pressupostos da aprendizagem ao longo da vida, ofereçam a esses sujeitos, particularmente às mulheres, oportunidades concretas 
de reinserção social e, por sua vez, a diminuição dos índices de reincidência criminal.

Esses são, a nosso ver, elementos-chave para o cumprimento dos direitos das pessoas encarceradas e, mais que isso, para a construção de alternativas emancipatórias para elas, desde a prisão até o retorno à sociedade.

\section{REFERÊNCIAS}

ALVES, M.; ANTUNES, F.; GOMES, E. X.; AFONSO, C. C.; PIRES, A.L. Aprendizagem ao longo da vida e politicas educativas europeias: tensóes e ambiguidades nos discursos e nas práticas dos estados, instituições e indivíduos. Caparica: UIED, Coleçáo Educação e Desenvolvimento, 2010.

ÁVILA, P. A literacia dos adultos: competências-chave na sociedade do conhecimento. 2005. Tese (Doutorado em Sociologia) - Instituto Superior de Ciências do Trabalho e da Empresa, Departamento de Sociologia, Lisboa, 2005.

BEZERRA, L.P.; BRAGA, R.; BATISTA, G.B. de M. O presídio Feminino Júlia Maranhão como espaço de atuação do Projeto Ressocialização Feminina, Cidadania e Direitos Humanos. In: XIV ENCONTRO DE EXTENSÃO (ENEX) E XV ENCONTRO DE INICIAÇÃO A DOCÊNCIA (ENID), 2013. A construção do conhecimento no cotidiano acadêmico: práticas e reflexōes. Disponível em: $<\underline{\text { http:// }}$ www.prac.ufpb.br/enex/trabalhos/3CCHLANCDHPROEXT2013324.pdf $>$. Acesso em: 08 jan. 2016.

BRASIL. Ministério da Educação. CNE. Parecer CNE/CEB n. 4, de 9 de março de 2010. Diretrizes Nacionais para a Oferta de Educação para Jovens e Adultos em Situação de Privação de Liberdade nos Estabelecimentos Penais. Disponível em: $\quad \leq h t t p: / / p o r t a l . m e c . g o v . b r / i n d e x . p h p ? o p t i o n=c o m ~ d o c m a n \& t a s k=d o c$ download\&gid=4445\&Itemid=>. Acesso em: 17 jul. 2012.

CERNEKA, H.A. Homens que menstruam: consideraçóes acerca do sistema prisional às especificidades da mulher. Veredas do Direito, Belo Horizonte, v. 6, n. 11, p. 61-78, jan.-jun. 2009.

CHIES, L.A.B. Cemitério dos vivos: análise sociológica de uma prisão de mulheres. Sociologias, Porto Alegre, n. 13, p. 338-345, jun., 2005. Disponível em <http://www.seer.ufrgs.br/index.php/sociologias/article/view/5515/3146>. Acesso em: 08 jan. 2016. 
CHIES, L.A.B.; VARELA, A.B. A Ambiguidade do Trabalho Prisional num Contexto de Encarceramento Feminino: o circulo vicioso da exclusão. In: XIII CONGRESSO BRASILEIRO DE SOCIOLOGIA. Sociedade Brasileira de Sociologia. 29 de maio a 01 de junho de 2007, UFPE, Recife (PE). GT30: Violência e Sociedade: segurança, controle e castigo. Anais... Pernambuco, 2007. Disponível em: $\leq$ http://www.sbsociologia.com.br/portal/index.php?option=com docman\&task=cat view\&gid=160\&Itemid=171>. Acesso em: 06 jan. 2016.

CUNHA, E.L. da. Ressocialização: o desafio da educaçáo no sistema prisional feminino. Cadernos Cedes, Campinas, vol. 30, n. 81, p. 157-178, mai.-ago. 2010. Disponível em <http://www.cedes.unicamp.br>. Acesso em: 09 jan. 2016.

DE MAEYER, M. Na prisão, existe a perspectiva da educação ao longo da vida? Alfabetização e cidadania. Revista de Educaçâo de Jovens e Adultos: diversidade do público da EJA, Brasília, n. 19, p. 17-37, jul. 2006.

A educação na prisão não é uma mera atividade. Educação \& Realidade, Porto Alegre, v. 38, n. 1, p. 113-136, jan.-mar. 2013. Disponível em: shttp:// www.ufrgs.br.edu_realidade $>$. Acesso em: 15 mar. 2013.

FRANÇA, M.H. de O. Criminalidade e prisão feminina: uma análise da questão de gênero. Revista Ártemis, v. 28, n. 1, p. 212-227, jul.-dez. 2014.

HADDAD, S. Os desafios da educação escolar e não escolar nas prisôes. In: YAMAMOTO, A. et al. (Orgs.). Educação em Prisóes. Cereja Discute: 1. São Paulo: Alfasol; Cereja, 2010. p. 65-67.

IRELAND, T.D.; LUCENA, H.H.R. O presídio feminino como espaço de aprendizagens. Educação \& Realidade, Porto Alegre, v. 38, n. 1, p. 113-136, jan./mar. 2013. Disponível em: $\leq$ http://www.ufrgs.br.edu realidade>. Acesso em: 15 mar. 2013.

JULIÃO, E. F. As políticas de educação para o sistema penitenciário: análise de uma experiência brasileira. In: ONOFRE, E.M.C. Educação escolar entre as grades. São Carlos: EdUFSCar, 2007. p. 29-49.

. Educação de Jovens e Adultos em Situação de Privação de Liberdade: desafios e perspectivas para a consolidaçáo de uma política nacional. In: DEFOURNY, V.; FONTANI, P.; IRELAND, T.; SIQUEIRA, I.; BAENA, C.; FLORES, P. (Org.). Educação em Prisóes na América Latina: Direito, Liberdade e Cidadania. Brasília: UNESCO, 2009, v. 1, p. 61-71.

LEMGRUBER, J. Cemitério dos vivos: análise sociológica de uma prisão para mulheres. Rio de Janeiro: Achiamé, 1983. 
LIMA, G.M.B.; PEREIRA NETO, A.F.; AMARANTE, P.D.C.; DIAS, M.D.; FERREIRA FILHA, M.O. Mulheres no cárcere: significados e práticas cotidianas de enfrentamento com ênfase na resiliência. Saúde em Debate, Rio de Janeiro, v. 37, n. 98, p. 51-61, jul.-set. 2013.

OLIVEIRA, M.G.F. de; SANTOS, A.F.P.R. dos. Desigualdade de gênero no sistema prisional: consideraçôes acerca das barreiras à realização de visitas e visitas íntimas às mulheres encarceradas. Caderno Espaço Feminino, UberlândiaMG, v. 25, n. 1, p. 236-246, jan.-jun. 2012.

ONOFRE, E.M.C. Educação escolar na prisão: controvérsias e caminhos para sair da cilada. In: LOURENÇO, A.S.; ONOFRE, E.M.C. (Orgs). O Espaço da prisáo e suas práticas educativas: enfoques e perspectivas contemporâneas. EdUFSCar: São Carlos, 2011. p. 267-285.

PIECK, E. Educação de Jovens e Adultos vinculada ao Trabalho. In: UNESCO. Declaração de Hamburgo. V Conferência Internacional de Educaçáo de Adultos - CONFINTEA V. Hamburgo, Alemanha, jul. 1997.

SILVA, R. O que as empresas podem fazer pela reabilitação do preso. São Paulo: Instituto Ethos, 2001. Disponível em: <http://www.ethos.org.br/ Uniethos/ Documents/manual_preso_internet.pdf $>$. Acesso em: 19 dez. 2012.

SOUZA, S.B. Criminalidade feminina: trajetórias e confluências na fala de presas do Talavera Bruce. Democracia Viva no 33. Ediçăo de out./dez. de 2006. Disponível em: <http://www.observatoriodeseguranca.org/files/dv33 artigo2. pdf $>$. Acesso em: 05 jan. 2016.

ORGANIZAÇÃO DAS NAÇÓES UNIDAS PARA A EDUCAÇÃO, A CIÊNCIA E A CULTURA (UNESCO). Declaração de Hamburgo. V Conferência Internacional de Educação de Adultos - CONFINTEA V. Hamburgo, Alemanha, jul. 1997.

Educação e aprendizagem para todos: olhares dos cinco continentes. Brasília: Ministério da Educação, 2009.

- Relatório global sobre aprendizagem e educação de adultos. Brasília: Ministério da Educação, 2010.

WANDERER, B. Do senso comum jurídico às funções latentes do trabalho prisional brasileiro. Universitas Jus, v. 23, n. 1, 2012. 


\section{NOTAS}

1. As mulheres reincidentes consideradas neste artigo se enquadram no grupo de reincidentes penitenciárias. A esse respeito, Juliāo (2009), baseado em estudos de Adorno e Bordini (1989) e Pinatel (1984), propóe a diferenciação dos tipos de reincidência, entre elas, a chamada reincidência penitenciária, aquela quando um egresso retorna ao sistema penitenciário após uma pena ou por medida de segurança.

2. Salientamos que, para preservar as identidades das entrevistadas, optamos por substituir os seus nomes reais por pseudônimos, escolhidos aleatoriamente entre as mulheres indígenas.

3. Além desses podemos mencionar: a resistência de agentes penitenciários e direçóes em relação ao direto à educação da pessoa presa, a desarticulação entre organismos do Estado, a falta de planejamento e políticas do Estado, o baixo investimento financeiro, a inexistência de um diagnóstico preciso sobre as pessoas presas, a falta de uma estrutura adequada mínima para instalação de salas de aula, etc.

Recebido em 11 de setembro de 2015.

Aceito em 22 de fevereiro de 2016. 